\title{
Article Type: Correspondence \\ Peri-operative lidocaine infusion for open radical prostatectomy - a reply
}

We thank Loadsman et al. for their important questions about our paper [1]. Regarding the primary outcome, using non-parametric testing the median (IQR) length of stay was 3.1 (2.9-3.8) days after lidocaine vs. 3.9 (3.0-4.9) days after saline $(\mathrm{p}=0.003)$. We agree that multiple outliers can skew any outcome measured; however, the three outliers did not impact on the significance level observed. Even with the three outliers excluded, the median (IQR) length of stay was 3.1 (2.8-3.8) days after lidocaine vs. $3.6(3-4.1)$ days after saline $(\mathrm{p}=0.01)$. No patients received oral opioids or other strong analgesics pre-operatively.

The mean (SD) duration of surgery was 155.7 (34.2) min in the lidocaine group and 141.6 (44.6) min for the saline group ( $\mathrm{p}=0.13$ ). Mean (SD) blood loss was higher in the lidocaine group: 1050.8 (750.9) $\mathrm{ml} \mathrm{vs.} 940.3$ (652.1) $\mathrm{ml}$ in the saline group (estimated difference $110 \mathrm{ml}, 95 \% \mathrm{CI}$ 218 to $439, \mathrm{p}=0.001$ ). However, only two patients in the lidocaine group and three patients in the saline group required a blood transfusion.

Loadsman et al. pointed out an important factual error regarding the stated date of the sample size calculation. The Statistical Centre at the University of Melbourne performethed sample size calculation, which was verified with the original ethically approved protocol, which states that sample size calculations were based on our institution's 2007 audit data. Data surveillance for patients undergoing elective radical prostatectomy who received morphine patient controlled analgesia alone had a mean (SD) duration of hospital stay of 108 (26) hours. Patients receiving morphine patient-controlled analgesia in addition to a systemic lidocaine infusion had a mean (SD) duration of hospital stay of 86 (26) hours.

The pain assessment tool described as a "ten millimetre" visual analogue scale (VAS) is incorrect. We thank you for pointing out this critical typographical mistake, which has been corrected in the manuscript. We used a horizontal VAS, $10 \mathrm{~cm}$ in length $(0=$ no pain, $10=$ worst possible pain) to score pain both at rest and during coughing at the incision site. Pain scores were

This is the author manuscript accepted for publication and has undergone full peer review but has not been through the copyediting, typesetting, pagination and proofreading process, which may lead to differences between this version and the Version of Record. Please cite this article as doi: $\underline{10.1111 / a n a e .13660}$

This article is protected by copyright. All rights reserved 
recorded at the discretion of an independent acute pain or ward nurse. When more than one score was documented within the same time period, this was averaged. As this was a pragmatic trial, pain scores were recorded at the clinical discretion of the nurse. All pain scores were analysed.

Importantly, nurses collecting pain data were blinded to treatment allocation, and we do not think the recording of pain scores compromised the integrity of the data.

Our findings are strongly suggestive of a difference in rest pain at the start of the measurement period. The mean VAS at rest at one hour postoperatively was 3.7 after saline and 1.9 after lidocaine (effect size 1.8, $\mathrm{p}=0.001,95 \%$ CI 0.7 to 2.9). Pain at rest was similar in both groups at $24 \mathrm{~h}$. The result for the analysis of the slopes over $24 \mathrm{~h}$ showed that the average change per hour in rest pain after saline (-0.15) was significantly greater than after lidocaine (mean change per hour of $-0.73, p=0.01 ; 95 \% \mathrm{CI}-0.14$ to -0.02 ). Pain during coughing was also analysed and represented in the same way as pain at rest. Again, these data are strongly suggestive of no difference in movement at the start of the measurement period, and this is confirmed by the analysis of the difference in the means at 3 hours postoperatively. The mean pain score during movement at 3 hours postoperatively for saline was 4.8, and for lidocaine, 3.7 units, a difference of 1.1 units ( $\mathrm{p}=$ 0.2). The $95 \% \mathrm{CI}$ for the true difference was -0.64 to 2.94 . The result for the analysis of the slopes is consistent with this. The mean change per hour in the saline group was similar to the lidocaine group ( $p=0.4$ ), with an average change per hour of -0.03 units. The $95 \%$ confidence interval for the true difference was -0.11 to -0.04 units.hr ${ }^{-1}$. The units have been corrected in the manuscript.

Patients' cumulative use of morphine was recorded by extracting morphine requirements documented in the post anaesthesia care unit and the pain charts. We collected data from each individual patient. Mean cumulative morphine use at each time point was documented. There were some missing data, which explains the multiple negative inflections, however all patients had cumulative total morphine use documented at 24 hours. The two groups were compared on this outcome. Cumulative morphine use is reported in the manuscript. As an alternative, but strongly related perspective, we compared the average rates of usage of morphine (per hour) in the two groups. To do this, regression analyses were carried out for each subject separately, using all the available data for each subject. The estimated slopes from these regressions were then used as an outcome. This approach to analysing these data, consisting of repeated measures on the same subjects, may be referred to as the 'summary measures' approach, outlined by Matthews et al. [2]. The mean for the saline group was $2.04 \mathrm{mg} \cdot \mathrm{hr}^{-1}$ and for lidocaine group was $1.41 \mathrm{mg} \cdot \mathrm{hr}^{-1}$. A standard two-sample t-test was used to compare the slopes. The saline group increased their morphine use by a mean of $0.62 \mathrm{mg} \cdot \mathrm{hr}^{-1}$ more than the lidocaine group. Note that $23 \times 0.624 \mathrm{mg}=$ $14.3 \mathrm{mg}$, which is close to the observed difference in means at 24 hours, namely, $13.9 \mathrm{mg}$. This

This article is protected by copyright. All rights reserved 
serves as a reminder that these two analyses are strongly associated; they are different perspectives rather than independent pieces of evidence.

We thank Loadsman et al. for their comments regarding the units for plasma lidocaine levels. The correct units are mcg. $\mathrm{ml}^{-1}$. Loadsman et al. are correct to point out our error regarding reference 14 .

\section{Weinberg}

Austin Hospital,

Melbourne, Australia.

D. Story

\section{Gordon}

\section{Christophi}

University of Melbourne,

Melbourne, Australia.

Email: Laurence.Weinberg@austin.org.au

No external funding and no conflicts of interest declared. Previously posted on the Anaesthesia correspondence website: www.anaesthesiacorrespondence.com

\section{References}

1. Weinberg L, Rachbuch C, Ting S, et al. A randomised controlled trial of peri-operative lidocaine infusions for open radical prostatectomy. Anaesthesia 2016; 71: 405-10.

2. Matthews JNS, Altman DG, Campbell MJ, Royston D. Analysis of serial measurements in medical research. British Medical Journal 1990; 300: 230-5.

\section{Editor-in-Chief's note}

The original article [1] has been corrected as per Dr. Weinberg's letter in this edition of the journal. 


\section{University Library}

\section{- M M I N E R VA A gateway to Melbourne's research publications}

Minerva Access is the Institutional Repository of The University of Melbourne

Author/s:

Weinberg, L;Story, D;Gordon, I;Christophi, C

Title:

Peri-operative lidocaine infusion for open radical prostatectomy - a reply

Date:

2016-10-01

Citation:

Weinberg, L., Story, D., Gordon, I. \& Christophi, C. (2016). Peri-operative lidocaine infusion for open radical prostatectomy - a reply. ANAESTHESIA, 71 (10), pp.1238-1239. https:// doi.org/10.1111/anae.13660.

Persistent Link:

http://hdl.handle.net/11343/291706 